\title{
The practice and design of social-ecological systems research
}

\author{
Alta de Vos, ${ }^{1}$ Kristine Maciejewski, ${ }^{2}$ Örjan Bodin, ${ }^{3}$ \\ Albert Norström, ${ }^{3}$ Maja Schlüter ${ }^{3}$ and Maria Tengö ${ }^{3}$ \\ ${ }^{1}$ DEPARTMENT OF ENVIRONMENTAL SCIENCE, RHODES UNIVERSITY, MAKHANDA, SOUTH AFRICA \\ ${ }^{2}$ CENTRE FOR SUSTAINABILITY TRANSITIONS, STELLENBOSCH UNIVERSITY, STELLENBOSCH, SOUTH AFRICA \\ ${ }^{3}$ STOCKHOLM RESILIENCE CENTRE, STOCKHOLM UNIVERSITY, STOCKHOLM, SWEDEN
}

\section{Introduction}

Studying social-ecological systems (SES) can be a challenging task, as explained in Chapter 2 . Phenomena of interest and characteristics of SES research result from both social and ecological processes, and complicated feedback dynamics blur the distinction between cause and effect (Young et al. 2006). Furthermore, multiple causal processes may be operating simultaneously, outcomes are strongly influenced by the system's context and it is difficult to determine system boundaries (Bodin and Prell 2011).

These challenges hold implications for the kinds of research approaches and methods used in SES research (Österblom et al. 2017; Preiser et al. 2018; Hazard et al. 2019). Intertwined SES cannot be understood from within a single discipline, and the context-dependent nature of systems means that generalisable laws are not easy to derive, or even appropriate, to use in SES research. Indeed, given the underlying motivation to inform change towards more sustainable futures, SES research often requires that researchers acknowledge the methodological pluralism that is necessary to understand the different dimensions and especially the interactions between the social and the ecological (Angelstam et al. 2013; Fischer et al. 2015; Preiser et al. 2018).

In response to these demands, the field of SES research draws on a large range of scientific theories and frameworks, and selects from a broad spectrum of methodologies (Fischer et al. 2015; Preiser et al. 2018). Researchers are often required to engage with a variety of stakeholders during the course of their projects. For this they will need to develop inter- and transdisciplinary teamwork skills (Angelstam et al. 2013; Roux et al. 2017) and an ability to engage with multiple knowledge types and values in participatory knowledge co-creation processes (Tengö et al. 2014). To operate in this space, SES researchers need an 'epistemological agility' (Haider et al. 2017) to engage with theories and frameworks from different disciplines that may require fundamentally different theoretical commitments and hold different assumptions, while also developing specific methodological competencies.

How then, do SES researchers develop this epistemological agility, navigate the broad range of theories, frameworks and methods that could potentially inform their study, decide on how 
much, and when, they need to engage with other disciplines and stakeholders, and develop their own research identity (Haider et al. 2017; Hazard et al. 2019)? To rise to this challenge, researchers have to recognise that SES research is an iterative and reflexive process for which there is no 'one-size-fits-all' approach (Hazard et al. 2019). Reflexivity here refers to a researcher's examination of how their personal beliefs, judgements, perceptions and worldview may influence research processes they are engaged in, and how these reflections are used to interpret research results within a particular context. Social-ecological systems researchers need to be aware of the assumptions and research traditions underlying the different frameworks, theories and methods they consider using. They have to understand that their research process, and the decisions they make in designing and executing their projects, should be strongly tied to the purpose of their research, which should, in turn, be strongly tied to the societal problem in question.

In this chapter, we attempt to guide the reflexive SES researcher through different components of an SES research project. We first discuss the identification of research problems, the purpose of the research and the SES research areas within which a researcher may be embedded. In many cases, these three factors will determine how researchers engage with frameworks, theories, methods and data; how they combine methods; and the extent to which they will collaborate with other researchers, disciplines and stakeholders (see Chapter 1). We also elaborate on more general issues relating to data generation, participatory research along a gradient of collaboration, and computational and mathematical modelling approaches, as these are common to a number of specific methods discussed in Part 2 of the book (Chapters 5-32). Finally, we consider practical ethics associated with SES research.

Our aim is not to provide a comprehensive overview of all the elements that can possibly be encountered in SES research (which will differ from study to study), but rather to provide general, practical principles for engaging with the SES research process.

\section{Elements of an SES research study}

The 'elements' that make up an SES research project are schematically represented in Figure 3.1. In designing and practising SES research, researchers identify problems, work within more specific research areas, draw on different theories and frameworks (which also draw on disciplinary theories), and use and generate different data types. There is no single path through these components and researchers may rely on multiple methods, theories and frameworks, combined and integrated in different ways. Individual SES studies often form part of larger inter- and transdisciplinary SES programmes.

Any project includes the identification of a problem or gap informing the research theme. Problem identification can happen in the 'traditional' way, where the researcher engages with the literature (including their own previous research) and identifies a gap that they would like to address. It may also be that a researcher is an expert in a particular methodology, and looks for (SES) problems to which this methodology can be applied. Alternatively, researchers may identify problems by engaging with policymakers, practitioners and other stakeholders, where the research problem is informed very directly by a societal need or gap. In these cases, problem identification may be an important part of the co-production process.

The researcher can also identify a problem by observing news, events and societal processes, sometimes through systematic, formal techniques such as horizon scanning and other 'futures' methods (Chapter 10). How the problem is identified (and which methods, theory and frameworks are ultimately chosen) will be strongly tied to the purpose of the research and the motivation of the researcher (Hazard et al. 2019). If a researcher is primarily 


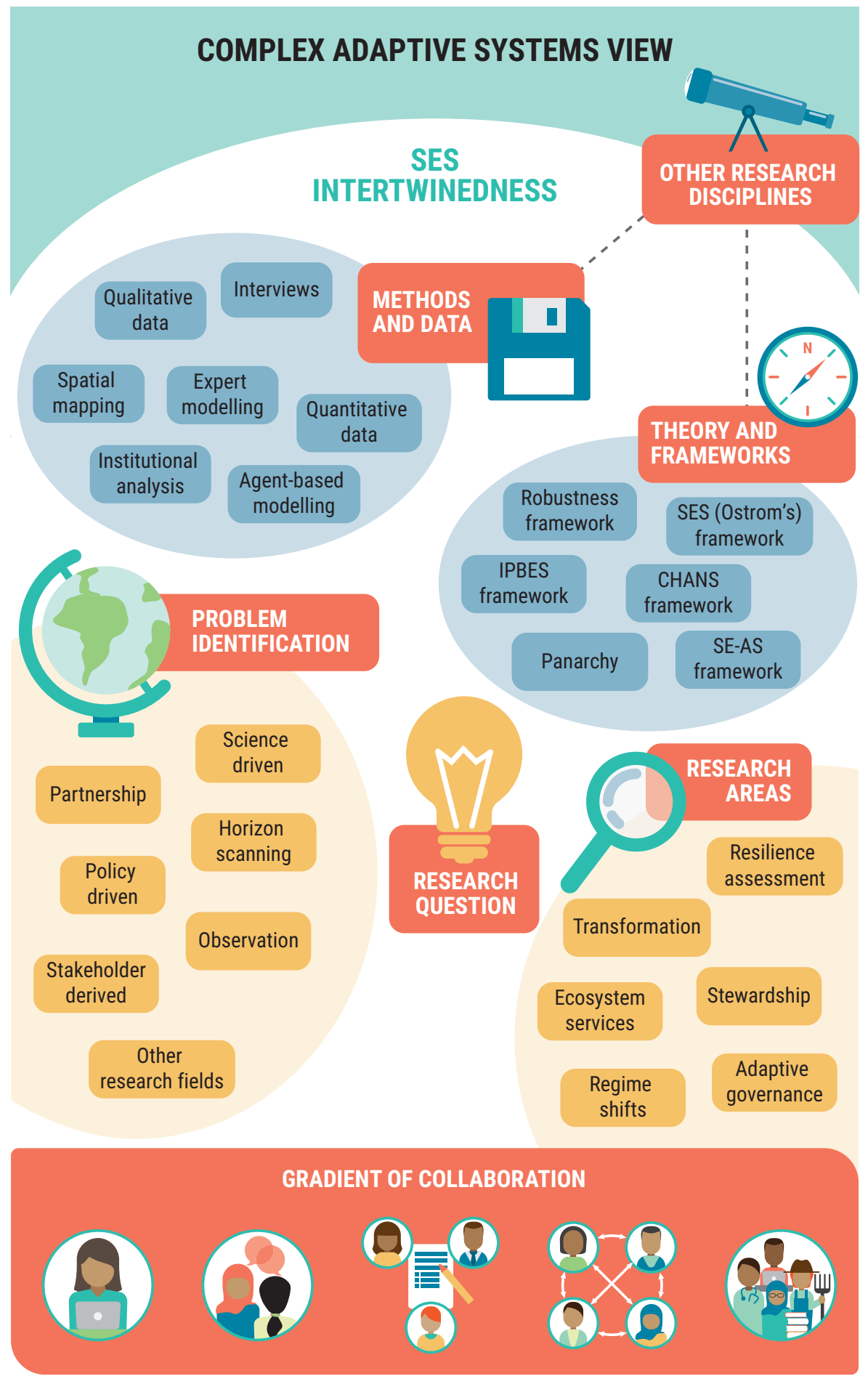

Figure 3.1 Key elements of SES research (@ Alta de Vos) 
interested in learning a new skill, they may opt for a project that applies that skill to a specific question. A researcher who is interested in affecting transformative change may seek out a mentor or collaborator who is engaged in a transdisciplinary project (see Section 'Working along a gradient of collaboration').

The way in which a research question or problem relates to theory, frameworks, methods and data is not fixed: frameworks may inform research questions, but research questions may also drive the selection of frameworks. Similarly, selected methods could inform or be informed by the research questions and frameworks used. In the SES research field, there are no strict rules or protocols about selecting frameworks and methods. As a result, researchers need to make choices and sometimes tough decisions about the methodological approach they want to take and the theories and frameworks they want to draw on. They will usually have to acknowledge that there are several and equally valuable understandings and approaches that can be adopted, depending on one's purpose and theoretical commitment. These choices and trade-offs can seem overwhelming but in practice they are often guided by the research areas in which a researcher is embedded.

Despite being relatively young (Binder et al. 2013; Pahl-Wostl et al. 2013; HerreroJáuregui et al. 2018; Colding and Barthel 2019; De Vos, Biggs, and Preiser 2019), the SES field has sprouted a number of specific research areas such as stewardship, resilience assessment, adaptive governance and transformation in the past 20-30 years. Within each of these areas, researchers typically approach social-ecological phenomena with a set of theories, frameworks and methods that have been developed, tested and debated in the literature. The study of regime shifts, for example, draws strongly on resilience theory (Chapter 14), often uses state-and-transition (Chapter 27) or dynamical systems models (Chapter 26), and frequently relies on remotely sensed data (Chapter 24) and interviews (Chapter 7). Whereas researchers can draw on approaches outside these bodies of knowledge, identifying existing methods used within particular research areas can save a lot of legwork in deciding which approaches may be most appropriate for any given study (although this could blind researchers to gaps in the field). In reality, very little SES research requires researchers to start 'from scratch' when it comes to deciding on their research approach.

\section{Frameworks, theories and methods}

Researchers across all disciplines use frameworks and theories to guide their study design and choice of methods (Meyfroidt et al. 2018; Schlüter et al. 2019), although not all research projects use these guiding tools, or use them a priori. Frameworks identify broad sets of SES elements and their linkages, guiding an investigation or activity by pointing to the concepts, elements, variables, links or processes that are characteristic of or critical for SES, or that help explain or predict SES outcomes. As discussed in Chapter 1, frameworks can be descriptive, analytical, or serve as boundary objects for interdisciplinary collaboration or heuristic problem solving (also see Meyfroidt 2016; Meyfroidt et al. 2018). Whereas some frameworks include assumptions about causal relationships between variables, they ultimately cannot posit causal inferences. Rather, they provide the 'ingredients' for theories that hypothesise about causal mechanisms and the relative weight and nature of interactions (Meyfroidt 2016; Meyfroidt et al. 2018; Bodin et al. 2019; Schlüter et al. 2019).

Universal theories that present testable hypotheses across a variety of contexts are not generally possible or desirable in SES research, given the social-ecological intertwinedness and context dependence that characterise the field (Schlüter et al. 2019). Instead, frameworks (particularly conceptual frameworks) are widely used and are often considered to be the 
'theoretical element' of SES research studies (Chapter 1). Recently, however, some researchers have started to look to middle-range theories to develop hypotheses that are valid under certain conditions, thus moving towards explaining, and not just describing, phenomena in systems (e.g. Meyfroidt et al. 2018; Bodin et al. 2019). Middle-range theories, still a frontier in SES research (see Chapter 33), can be defined as 'contextual generalizations that describe chains of causal mechanisms explaining a well-bounded range of phenomena, as well as the conditions that trigger, enable, or prevent these causal chains' (Meyfroidt et al. 2018, 53). Middle-range theories thus seek to provide testable hypotheses within very specific and well-defined contexts, striking a balance between ungeneralisable detailed single-case research and universal theories that aim to explain phenomena across and in all general contexts (Meyfroidt et al. 2018; Bodin et al. 2019; Schlüter et al. 2019).

Methods are codified ways of producing knowledge of a focus of interest. They are specific information-generating practices to generate and analyse data (Pahl-Wostl et al. 2013; Stirling 2015). Although frameworks (along with theories and research areas) often guide the selection of methods, not all methods are underpinned or informed by 'formal' frameworks (as discussed above and in Chapter 1). Nevertheless, all methods reflect the underlying values and beliefs of researchers (Poteete, Janssen, and Ostrom 2010) and rely on assumptions that constrain the contexts in which generated knowledge is useful and the degree to which it can be used to make truth claims. Most network analyses (Chapter 23), for example, assume complete knowledge of all connections in a network. Although network analysis is inordinately useful for understanding problems such as disease spread through an agricultural system (e.g. Moore, Grewar, and Cumming 2016) or how the structure and function of natural resource governance systems are linked (Bodin et al. 2019), it may not be a useful method in systems where many of the key actors, or the relationships between them, cannot easily be known. Similarly, many participatory mapping exercises (Chapter 8) assume that participants are able to relate to spatial constructs in their world through reading maps or interacting with a virtual globe. This may not be true in all communities, or there may be some groups more able to engage in this way than others (e.g. Weyer, Bezerra, and De Vos 2019), which may undermine the internal validity of the collected data and the objectives of the participatory process. Finally, models based on economic theory make many simplifying assumptions about the nature of human decision-making (e.g. that the context in which individuals are embedded does not affect their decisions [methodological individualism]). These assumptions may be appropriate in very narrow and controlled contexts where a specific element of the system is under investigation in a specific context (see examples in Chapter 21), but it may be inappropriate to generalise these findings to other contexts or to use these methods to understand complex dynamics in systems.

\section{Combining multiple methods}

Given the limited extent to which individual methods can be used to understand SES (Poteete, Janssen, and Ostrom 2010; Preiser et al. 2018), research projects and knowledge co-production processes (see Section 'Working along a gradient of collaboration') often rely on more than one method to achieve their goals (Murray, D'Anna, and MacDonald 2016). At its broadest, multi-method research simply refers to the use of more than one method to understand given phenomena (Anguera et al. 2018) and does not necessarily mean that those methods are integrated or used for triangulation. In the CreativeVoice approach, for example, photos, videos, songs, drawing and paintings are combined to allow more participants to engage with an expressive art form (Rivera Lopez, Wickson, and Hausner 2018). 
Similarly, ecological data collection methods (Chapter 6) may be used in combination with interviews and surveys (Chapter 7), sometimes with a view to understanding different aspects of the system rather than understanding the same process or dynamic from a complementary perspective.

In many cases, however, SES researchers explicitly use multi-method designs to integrate different methods by applying mixed-methods and multi-method triangulation approaches. A mixed-methods study is one where the researcher combines a quantitative method and a qualitative method to analyse data (McKim 2017) and integrates these to understand and interpret a particular problem based on the combined strengths of both datasets (Tashakkori and Teddlie 1998; Creswell 2014; Cox 2015). Given the fundamentally different assumptions that typically underlie quantitative and qualitative methods, mixed-methods approaches require careful design and consideration about how and when to 'mix' quantitative and qualitative data (for some suggestions, see Leech and Onwuegbuzie 2009; Teddlie and Tashakkori 2011; Creswell 2014; Cox 2015).

Multi-method triangulation is also usually integrative (Meijer, Verloop, and Beijaard 2002) and specifically refers to approaches where insights regarding a single research problem are strategically drawn from findings generated using different methods (Young et al. 2006; Munafò and Davey Smith 2018). Multi-method triangulation differs from mixed-methods approaches in that it does not necessarily entail integrating quantitative and qualitative methods, but could integrate any set of different methods. Triangulation assumes that researchers can generate a broader span of insights or acquire more support for a potential explanation of a complex phenomenon by relying on different methods. Since every method has its own assumptions, strengths and weaknesses, combining different methods can help to reveal different aspects of phenomena being investigated and can compensate for the limitations of individual methods.

The triangulation of methods can have different objectives and ambitions. A strongly integrative ambition relates to integrating theories, methods and data from different disciplines or knowledge traditions. This approach, known as unification, requires a researcher to consider the theoretical assumptions that underlie methods and, in doing so, start integrating theories (Popa and Guillermin 2017; Persson et al. 2018). Unification can be very rewarding and facilitate new theoretical breakthroughs, particularly when the methods being integrated have similar underlying assumptions (e.g. combining theories of collapse with resilience theory; Cumming and Peterson 2017). However, a unification approach can also lead to indirectly compromising or disregarding the important assumptions that underlie methods (Popa and Guillermin 2017; Persson et al. 2018; Jerneck and Olsson 2020).

A less integrative ambition of triangulation, and one more broadly used and advocated for in SES research (e.g. Norgaard 1989; Popa and Guillermin 2017; Persson et al. 2018; Jerneck and Olsson 2020) builds on pluralism. Pluralism refers to the use of different methods with the aim of investigating a common phenomenon but from different perspectives (e.g. assessing land-use change through remote sensing, interviews, focus groups and participatory mapping; Achieng et al. 2020). Pluralism underscores the autonomy of different methods, along with their associated assumptions and theories. Thus, pluralism is less integrative and less focused on unifying perspectives across disciplinary and knowledge system boundaries. A pluralistic approach is particularly appropriate in knowledge co-production processes where system understanding relies not only on methods from different disciplines but also on different knowledge systems, which may not hold equal power in decision-making. In these processes, it is desirable to 'weave' results from different methods based in different disciplines and knowledge systems, rather than cross-validating one system with another, or unifying them (Tengö et al. 2014). 


\section{Data in SES research}

As with other choices in SES research, the way in which SES researchers engage with data will depend on the purpose of their research, the motivation of the researchers, the theories and frameworks they employ, their guiding methodology and the available funding. The data used in a particular study will also depend on where the project lies on a 'gradient of intertwinedness': the kind of data used to understand ecological feedbacks resulting from social processes, for example, will be different to the data used in a project setting out to understand social feedbacks resulting from social processes in the context of ecological processes. While multi-method approaches that use different data types are useful in overcoming some of the challenges of SES research, these approaches are also more expensive, conceptually challenging and time consuming, and should not automatically be adopted as the best option in all cases (Creswell 2014; McKim 2017).

In SES research, quantitative and qualitative data can be generated in a number of different ways. In this book, we discuss methods that use the following types of data:

- Empirical field data collected through ecological field data collection (Chapter 6), interviews and surveys (Chapter 7), participatory data collection methods (Chapter 8), controlled behavioural experiments (Chapter 21) or methods used for historical assessment (Chapter 25)

- Co-produced data generated through participatory data collection methods (Chapter 8), action research (Chapter 15), facilitated dialogues (Chapter 9), futures analysis (Chapter 10), scenario development (Chapter 11), serious games (Chapter 12), participatory modelling (Chapter 13) and resilience assessment (Chapter 14)

- Textual and archival data (e.g. photographs and audio) retrieved from published scientific papers and governmental and other policy documents and repositories. These data are stored in libraries, databases and archives and are used in qualitative content analysis (Chapter 19), comparative case study analysis (Chapter 20), institutional analysis (Chapter 22) and historical assessment (Chapter 25)

- Mined and synthesised data (often 'big data') using natural-language processing and other pattern-recognition methods (Chapter 17), or through large-scale meta-analysis methods (Chapter 19)

- Simulated data produced using dynamical systems models that simulate dynamic systems numerically (Chapter 26), agent-based modelling (Chapter 28), statistical models (Chapter 18), ecosystem service modelling (Chapter 31) or expert modelling (Chapter 16)

- Downloaded datasets from public and other databases, including government census data, health and demographic data and remote-sensing and GIS data from a diversity of sectors, compiled case studies and interviews. A collection of platforms commonly used by SES researchers to access useful datasets is given in Table 3.1, and is also provided online (sesmethods.org).

All the data types listed here can include spatial data (Chapter 24). Participatory mapping and GPS-based plots, for example, can be used to co-produce or collect spatial data, remotely sensed spatial data can be synthesised into analysable products, dynamic simulation models can be spatially explicit, and many downloadable SES datasets include spatial data. 
Alta de Vos et al.

Table 3.1 Examples of existing datasets commonly used in SES research, and the platforms where they can be sourced

\begin{tabular}{|c|c|}
\hline pe & $e(s)$ \\
\hline $\begin{array}{l}\text { Remotely } \\
\text { sensed data } \\
\text { and global } \\
\text { spatial data }\end{array}$ & $\begin{array}{l}\text { - Google Earth Engine: earth-engine/datasets/catalog } \\
\text { - Bio-Oracle: bio-oracle.org } \\
\text { - Microsoft Earth: microsoft.com/en-us/ai/ai-for-earth-tech-resources } \\
\text { - World Resource Institute: datasets.wri.org } \\
\text { - NASA's Socioeconomic Data and Applications Centre: sedac.ciesin.columbia.edu/ } \\
\text { data/sets }\end{array}$ \\
\hline $\begin{array}{l}\text { Protected } \\
\text { areas }\end{array}$ & $\begin{array}{l}\text { - Protected Planet: protectedplanet.net } \\
\text { - PADDD (Protected Area Downgrading, Downsizing and Degazettement) tracker: } \\
\text { padddtracker.org }\end{array}$ \\
\hline $\begin{array}{l}\text { Biodiversity } \\
\text { data }\end{array}$ & $\begin{array}{l}\text { - Global Biodiversity Information Facility: gbif.org } \\
\text { - IUCN Red List of Species and Ecosystems: iucnredlist.org; iucnrle.org } \\
\text { - Projecting Responses of Ecological Diversity in Changing Terrestrial Systems } \\
\text { (Predicts): predicts.org.uk } \\
\text { - The Living Planet Index (LPI): livingplanetindex.org } \\
\text { - Nature Map Explorer: explorer.naturemap.earth/map } \\
\text { - Map of Life: mol.org }\end{array}$ \\
\hline Human impact & $\begin{array}{l}\text { - Global Human Footprint: ghsl.jrc.ec.europa.eu/datasets.php } \\
\text { - JRC global human settlement layers: ghsl.jrc.ec.europa.eu/datasets.php } \\
\text { - Global Human Modification Map (also see 'Remotely sensed data and global } \\
\text { spatial data' above): Global_Human_Modification/728308 } \\
\text { - Anthropogenic Biomes (also see 'Remotely sensed data and global spatial data'): } \\
\text { ecotope.org/anthromes/faq }\end{array}$ \\
\hline $\begin{array}{l}\text { Development } \\
\text { and livelihood } \\
\text { data }\end{array}$ & $\begin{array}{l}\text { - World Bank: data.worldbank.org } \\
\text { - CIFOR's Poverty and Environment Network (PEN) global dataset: data.cifor.org/ } \\
\text { dataset } \\
\text { - USAID demographic and health surveys (DHS): dhsprogram.com/data } \\
\text { - USAID Development Data Library: data.usaid.gov } \\
\text { - FLARE network (Forests \& Livelihoods: Assessment, Research, and Engagement): } \\
\text { forestlivelihoods.org/resources } \\
\text { - Comtrade: comtrade.un.org/labs } \\
\text { - Food and Agricultural Organization (FAO): fao.org/statistics/databases/en } \\
\text { - World Resource Institute data: datasets.wri.org }\end{array}$ \\
\hline $\begin{array}{l}\text { Case study } \\
\text { databases }\end{array}$ & $\begin{array}{l}\text { - Social-Ecological Systems Meta-Analysis Database (SESMAD): sesmad.dartmouth.edu } \\
\text { - SES Library: seslibrary.asu.edu/case } \\
\text { - Regime Shift Database: regimeshifts.org } \\
\text { - Resilience Alliance Thresholds database: resalliance.org/thresholds-db } \\
\text { - Engage2020 Action Catalogue: actioncatalogue.eu/about } \\
\text { - ISeeChange: Thresholds Database: iseechange.org } \\
\text { - Digital Library of the Commons: dlc.dlib.indiana.edu/dlc } \\
\end{array}$ \\
\hline $\begin{array}{l}\text { Models and } \\
\text { methods }\end{array}$ & $\begin{array}{l}\text { - COMSES (Netlogo) models: comses.net } \\
\text { - Bayes Net Library: norsys.com/netlibrary/index.htm } \\
\text { - SES models: actioncatalogue.eu/about } \\
\text { - Engage2020 Action Catalogue: modelingcommons.org }\end{array}$ \\
\hline Water & $\begin{array}{l}\text { - Water Footprint Network: gwp.org/en/learn/iwrm-toolbox } \\
\text { - IWRM Toolbox (see 'Remotely sensed data and global spatial data'): } \\
\text { waterfootprint.org/en/resources/waterstat }\end{array}$ \\
\hline
\end{tabular}




\begin{tabular}{ll} 
Type & Source and website(s) \\
\hline Climate & - Climate variability and predictability database (CLIVAR - Climate and Ocean: \\
& Variability, Predictability and Change): clivar.org/resources/data \\
& $\begin{array}{l}\text { Participatory database on climate change impacts (see 'Remotely sensed data } \\
\text { and global spatial data'): iseechange.org }\end{array}$ \\
\hline Other & - \\
\hline
\end{tabular}

A more descriptive list can be found at sesmethods.org

\section{Dynamic modelling in SES research}

Dynamic modelling using analytical or computational/simulation approaches is a key approach to studying complex systems. It is particularly suitable for analysing the dynamics of SES, such as the equilibria of a system or the way in which a system unfolds over time from the interplay of social and ecological processes. Modelling allows for experimenting with an SES in ways that are not possible with real systems. Models and simulation experiments can, for example, be used to assess possible intended and unintended consequences of the introduction of a new policy, to unravel the mechanisms that may have generated an outcome of interest, or to assess the uncertainty of outcomes that results from limited knowledge about key processes (such as human decision-making) or the stochastic and emergent nature of SES. Simple mathematical models have been extensively used from the early days of resilience research to study multiple equilibria and regime shifts in ecological systems, and increasingly also SES. Simulation models (e.g. system dynamics or agent-based models) are often used to study the behaviour of particular SES such as a landscape or a fishery that emerges from the interactions of different SES elements.

Models and the modelling process itself can serve many different purposes. They can be used to enhance understanding of SES dynamics; to explore, explain or predict SES outcomes (Edmonds 2017); to facilitate interdisciplinary communication and integration; or to serve as boundary objects in participatory processes (see Chapter 13) (Schlüter, Müller, and Frank 2019; Schlüter et al. 2019). Models can also play different roles in a research or participatory process: they can be used as a thinking tool to support reflection about different beliefs or views of the system or processes of interest and their consequences for system behaviour; as a tool for exploration, e.g. of possible consequences of an intervention; as a tool for eye opening or myth busting; as a tool for explaining social-ecological phenomena of interest by testing possible mechanisms; as an analytical tool to identify generic processes or principles that determine SES behaviour; or as a tool for assessing the effects of policies or the implications of global change (Schlüter, Müller, and Frank 2019). The use of models for policy assessment, for exploring the behaviour of SES as a complex (adaptive) system, and for participatory processes is probably the most common model applications in SES research to date. Although dynamic models can be used to make predictions or to help test and develop theories by formalising and exploring relations between different variables and their outcomes, they are currently very rarely used in this way in SES research.

Models can be theoretical, based on generic processes such as population growth and utility maximisation with the aim to understand the general behaviour of a system, or empirical, based on empirical data and processes with the aim to understand a system's behaviour or response in a particular place. Some models may combine both, for example by using theoretical models where data and knowledge are limited and empirically informed models for other aspects of the system. Stylised or toy models that represent selected aspects of a system 
in a generic way (often based on insights that hold across different cases but are not necessarily derived from theory) to investigate their impact on SES outcomes are also commonly used. The most common type of modelling used in SES research is dynamical systems modelling, agent-based modelling and state-and-transition modelling. These models differ in how they study the change of the system over time, how and at what level of aggregation they represent a system and how they go about to find solutions or generate the outcomes of the model (for an overview of different common model types, see Schlüter, Müller and Frank 2019). While they can all be used for different purposes and roles, some are more suitable to achieving a given research aim than others.

Contrary to the large-scale simulation models that dominate in Earth systems and climate change research, and to models used in theoretical ecology or economics, many SES models are developed from scratch. This means the researcher or research team goes through all the modelling steps - from collecting and eliciting data and empirical evidence or relevant theoretical models to developing a conceptual model; formalising the model in equations or computer code; testing, verifying and validating the model; running simulations or doing mathematical analyses; analysing the model and communicating the results. These different steps require many different skills, knowledge and methods. The process of building the model, i.e. decisions on what variables/actors and processes/interactions to include, and how to represent functional relationships are major parts of the modelling process. This process is often as valuable as the resulting model as it challenges participants to make explicit their assumptions and understanding about the SES or problem of interest, ideally in a collaborative endeavour that involves a diversity of scientific and non-scientific participants, drawing on different knowledge systems (Schlüter, Müller, and Frank 2019; Schlïter et al. 2019). This is one of the main advantages of co-developing models with stakeholders, as it can facilitate building shared understanding and learning. Similarly, codeveloping models with scientists from different disciplinary backgrounds can support a reflective and reflexive approach and thoughtful interdisciplinary integration.

\section{Working along a gradient of collaboration}

As explained in Chapter 2, the complex, intertwined nature of SES demands intellectual humility from researchers and a shift in their approach to knowledge development, learning and the ways in which they support policy and change (Audouin et al. 2013; Preiser et al. 2018). Investigating the intertwined human and biophysical dimensions of SES problems requires knowledge on the multi-scale interactions between ecosystems and society (Angelstam et al. 2013; Nash et al. 2017), which demands diverse expertise from many different disciplines and often also requires engagement with key actors and stakeholders engaged in SES governance and management. Collaboration and knowledge co-production with non-academic societal actors are particularly important for SES projects where concrete societal change, and not just knowledge development, is the main objective (e.g. action research (Chapter 15)).

Thus, although SES research can be a solitary practice, it often entails collaboration and working in teams. Teams that only involve academics, but from different disciplines, are commonly referred to as interdisciplinary teams. In these teams, researchers work together to integrate or combine disciplinary knowledge and methods, develop and meet shared goals, and achieve synthetic understanding of a problem or system. In other cases, the sphere of collaboration is expanded to include relevant stakeholders and other non-academics to form transdisciplinary teams (Lang et al. 2012; Angelstam et al. 2013). Research for action, in which supporting and facilitating societal change may be the most important project objectives, is mostly conducted in transdisciplinary teams. 
Working in diverse teams has many benefits, the most notable of which is integrating multiple ways of knowing and doing to generate a more comprehensive understanding of complex social-ecological challenges. However, there is also a suite of well-recognised challenges to working in teams (Lang et al. 2012; Kelly et al. 2019). Interdisciplinary work, for example, often requires time and resources to define, understand and combine the disparate concepts and methods upon which diverse disciplines are founded. These intellectual transaction costs can trigger tensions within interdisciplinary teams. Working across disciplines requires practices, attitudes and personality traits such as humility, respectfulness, open-mindedness, patience and the willingness to embrace complexity (Kelly et al. 2019). While these 'soft skills' are consistently identified as critical for collaboration among disciplines and knowledge systems, they are rarely valued or specifically recognised and developed within disciplinary research training (Kelly et al. 2019). Fortunately, the growing number of interdisciplinary projects is generating a growing repository of practical advice to support researchers and institutions wishing to embrace interdisciplinary social-ecological research, as well as scholars with experience in working in interdisciplinary teams.

Working beyond academic boundaries to collaborate with stakeholders such as government officials, community members and civic society organisations often introduces further challenges. Collaborations with stakeholders and other non-academic actors are often seen as pathways to making social-ecological research both more democratic through stakeholder involvement and more impactful by creating ownership and tying it to actions that benefit those stakeholders. In practice, there is a continuum of stakeholder involvement (or participation) (Cvitanovic et al. 2019). At the one end of the spectrum, participation can be limited to very low levels of engagement, where stakeholders merely provide data for a research project (e.g. citizen science) or evaluative feedback on research products, or are informed about research outcomes. While these types of consultative engagements can be useful, they have been criticised for leading to 'token participation' that does not treat non-academics as full partners in the research process, and potentially undermine the extent to which the benefits of participation are conferred.

At the other end of the spectrum of participation is a loosely linked and evolving cluster of approaches that include knowledge co-production and transdisciplinary research (Lang et al. 2012; Wyborn et al. 2019; Norström et al. 2020). These approaches reject the archetypal model of academic knowledge production, where researchers identify problems, carry out research to address them and then communicate this new knowledge to society to be acted upon. The goals of these new forms of participatory approaches are to co-produce knowledge and solutions with, and for, decision-makers and other actors in society. These knowledge co-production processes can facilitate robust solutions to sustainability challenges and their effective and equitable implementation (Norström et al. 2020) by providing a richer, more diverse and more legitimate understanding of the multiple drivers, interdependencies and complexities of SES dynamics and challenges, and of the decision contexts in which research is to be applied (Tengö et al. 2012).

Knowledge co-production holds strong potential for addressing sustainability challenges, but adds new demands and requires new skills to make collaborative research practice successful. A number of critical issues need to be considered and carefully managed to avoid serious pitfalls that end up doing more harm than good. First, who are the actors with whom the researcher wants to engage, and what do they represent? Knowledge co-production needs to explicitly recognise a range of perspectives, knowledge and expertise and build awareness of gender, ethnicity and age-related aspects of who is involved - or left out. This poses a variety of new ethical concerns (Bohle and Preiser 2019; also see Chapter 2, and Section 'Practical 
and procedural ethics'). The leaders of a co-production process face the task of assembling an appropriately broad or inclusive set of relevant actors, while keeping the process manageable within practical and strategic limits. There may be tensions between actor groups, for example. If that happens, a step-wise approach to participation, where smaller groups are initially convened before a broader group is engaged, may reduce potential points of conflict or allow some facilitating steps to be undertaken.

Second, is the researcher engaging with key stakeholders, key knowledge holders or actors in key positions to implement knowledge? Different objectives or targets of the research may entail different approaches to identifying and actively engaging with actors. This will also have implications for the design of the collaboration - the kinds of interfaces and the types of meetings and activities that are used to facilitate knowledge exchange and learning.

Third, how is the researcher interacting with, and handling, existing power dynamics between actors in collaborative processes? A failure to sufficiently engage with power imbalances can undermine the quality of the engagement and the outcomes, and can derail the entire exercise. These challenges can be addressed by taking the necessary steps to build trust and reveal tensions and expectations between collaborators before the actual phase of knowledge generation begins. Co-produced social-ecological research also needs to understand the historical context of how a particular challenge emerged, who will be affected by the process and its outcome, and how regulatory, institutional and cultural factors will shape the process and the realisation of desired outcomes. Successful co-production is often built on legacies of the past (conceptual insights obtained in previous projects, long-established research sites, earlier relationships with stakeholders) that can all help to provide insights into the context of the current project. Thus, as an early career researcher, it may be valuable to connect with existing networks and relationships.

Finally, as in any team effort, high-quality co-production processes require frequent interaction of participants throughout the process. Interactive exchanges between participants nurture ongoing learning, build trust and increase the salience and legitimacy of generated knowledge.

\section{Practical and procedural ethics}

Applying an SES lens to understanding the world has profound ethical implications for how researchers engage with their research projects (also see Chapter 2). A complex adaptive systems perspective and the desire to affect transformative change means that research projects often seek to engage novel forms of collaborative agency through participatory and collaborative multi-stakeholder processes that foster dialogue and knowledge co-creation (Preiser et al. 2018). These approaches and processes have implications for how researchers engage not only in their research projects (or day-to-day 'practical ethics'; Rossman and Rallis 2010) but also with official processes to obtain permission to carry out their studies (procedural ethics).

Social-ecological systems researchers based at universities (as students or staff members) are usually required to obtain ethical clearance and conduct their studies according to the rules of the institution. Most universities have registered ethics committees that are required to adhere to standards set by a higher (state, provincial or national) regulatory body. Clearance from these committees is required before data collection can commence. It must also be shown that the correct process was followed before a degree can be awarded or the results eventually published. The process of applying for ethical clearance for data collection can cause significant delays in getting projects under way. Ethics committees cannot always process applications quickly, and SES research processes, especially where they involve 
transdisciplinary knowledge co-production, can raise additional questions that can take time to resolve because they are different to conventional research approaches (Cockburn and Cundill 2018). Since SES researchers may have ecological and social components to their research design, they may have to apply for clearance to more than one committee.

Procedural ethics may pose a particular obstacle to transdisciplinary research projects. In most institutions, current research ethics clearance processes are designed for administering research approaches (e.g. surveys) where societal actors only become involved during the data collection phase, and usually as subjects and not participants (Locke, Alcorn, and O’Neill 2013; Cockburn and Cundill 2018). Transdisciplinary research processes are often at odds with procedural ethics, particularly with regard to 'informed consent', which is seen as a one-off activity rather than being negotiated through an ongoing process with research stakeholders (Banks et al. 2013; Locke, Alcorn, and O'Neill 2013; Cockburn and Cundill 2018). Co-production of knowledge and participatory methods can also make it very hard to know who the data belong to and how and where to ethically store the data (Rambaldi et al. 2006; Cockburn and Cundill 2018).

While certain institutional reforms would make for easier procedural practices (Cockburn and Cundill 2018), it is critical to recognise that formal institutional processes and documents will never be able to provide full ethical guidance and standards for SES research projects (Rossman and Rallis 2010; Coburn and Cundill 2018). Procedural ethics can provide some of the principles of ethical engagement, and play an important role in holding individuals and institutions accountable (Cockburn and Cundill 2018). However, researchers themselves are ultimately responsible for the moral considerations and ethical choices they make as part of their daily practice (Rossman and Rallis 2010) throughout their project. In practice, this means that SES researchers need to develop and reflect on their own personal ethics principles for engaging in their project right from the scoping phases, and continue to do so throughout the project (Cockburn and Cundill 2018). The principles they might draw upon will vary according to context, but can include elements such as respect for and the dignity of research participants, transparency and honesty, accountability and responsibility of the researcher, integrity and academic professionalism (Cockburn and Cundill 2018), and sensitivity to power imbalances and the potential impacts of transformative change (Shah et al. 2018). Being an ethical SES researcher requires one to be reflexive (reflecting and reacting) on one's practice not only individually (e.g. by journalling; Meyer and Willis 2019) but also through conversations with advisers, mentors and research participants, and through engaging with reflective peer groups on transdisciplinary research practice, for example (Cockburn and Cundill 2018).

Everyday practical ethics is important in all SES projects, not only for SES researchers engaged in transdisciplinary or participatory projects. In some SES projects, procedural ethics may not be required and the ethical consequences of research may not be immediately obvious. Projects may, for example, have various indirect ecological and social consequences when management decisions flow from interactions between researchers and managers, or when changing the relationship between a community and nature (Schlaepfer, Pascal, and Davis 2011). Big data, natural-language processing and other machine-learning techniques are now becoming commonplace in many global SES studies (Skibins et al. 2012; Di Minin, Tenkanen, and Toivonen 2015). Although these data are in the public domain and thus do not usually require ethical approval, processing and presenting these data can pose severe ethical concerns regarding informed consent, privacy, ownership, objectivity, intellectual property and group-level ethical harms (Mittelstadt and Floridi 2016). Studies that use social media to investigate perceptions of nature, for example, may be biased towards the 
perception of certain demographics (Di Minin, Tenkanen, and Toivonen 2015). Similarly, remote-sensing data available at global scales could be used to inform policies that are misaligned with local contexts (Veldman et al. 2019). The SES researcher thus has to recognise and take responsibility for the fact that every decision about data collection, analysis, interpretation and presentation has moral dimensions, and that these decisions are ongoing (Rossman and Rallis 2010).

\section{Conclusion}

This chapter describes the research landscape that SES researchers navigate when designing and executing their projects. The complex and problem-focused nature of SES research means that researchers have many potential frameworks, theories and methods to choose from, each with their own underlying research traditions and assumptions. Rather than getting overwhelmed by the methodological and epistemological options available, we encourage researchers to define and reflect on the purpose of their research and their ultimate motivations and desired outcomes. With such a reflexive attitude, the researcher can draw further guidance from appropriate frameworks and methods to use in a particular context, based on the particular SES research area within which they are working. They may find themselves in trans- and interdisciplinary collaborations, which will require the development of additional skill sets that are not always well supported by formal graduate training programmes.

Finally, the often collaborative nature of SES research presents significant ethical considerations, particularly as research projects often actively seek to effect actions and change towards sustainability. Regardless of whether they are conducting a mono-, multi-, inter- or transdisciplinary study, the reflective SES researcher recognises that every methodological and theoretical decision is ultimately an ethical one that will have consequences for their understanding of SES, and actions towards sustainability.

\section{Acknowledgements}

Alta de Vos received support from a Rhodes University Council Grant. Maja Schlüter received support from the European Research Council under the European Union's Horizon 2020 research and innovation programme (grant agreement no. 682472 - MUSES). Albert Norström received support from the Swedish Research Council FORMAS (grant no. 201701326) and the GRAID programme at the Stockholm Resilience Centre.

\section{References}

Achieng, T., K. Maciejewski, M. Dyer, and R. Biggs. 2020. 'Using a Social-Ecological Regime Shift Approach to Understand the Transition from Livestock to Game Farming in the Eastern Cape, South Africa.' Land 9(4): 97. doi:10.3390/land9040097.

Angelstam, P., K. Andersson, M. Annerstedt, R. Axelsson, M. Elbakidze, P. Garrido, P. Grahn et al. 2013. 'Solving Problems in Social-Ecological Systems: Definition, Practice and Barriers of Transdisciplinary Research.' Ambio 42(2): 254-265. doi:10.1007/s13280-012-0372-4.

Anguera, M.T., A. Blanco-Villaseñor, J.L. Losada, P. Sánchez-Algarra, and A.J. Onwuegbuzie. 2018. 'Revisiting the Difference between Mixed Methods and Multimethods: Is It All in the Name?' Quality and Quantity 52(6): 2757-2770. doi:10.1007/s11135-018-0700-2.

Audouin, M., R. Preiser, S. Nienaber, L. Downsborough, J. Lanz, and S. Mavengahama. 2013. 'Exploring the Implications of Critical Complexity for the Study of Socialecological Systems.' Ecology and Society 18(3): 12. doi:10.5751/ES-05434-180312. 
Banks, S., A. Armstrong, K. Carter, H. Graham, P. Hayward, A. Henry, T. Holland et al. 2013. 'Everyday Ethics in Community-Based Participatory Research.' Contemporary Social Science. doi:10.10 80/21582041.2013.769618.

Binder, C.R., J. Hinkel, P.W.G. Bots, and C. Pahl-Wostl. Claudia. 2013. 'Comparison of Frameworks for Analyzing Social-Ecological Systems.' Ecology and Society 18(4): 26. www.ecologyandsociety. org/vol18/iss4/art26.

Bodin, Ö., and C. Prell. 2011. Social Networks and Natural Resource Management: Uncovering the Social Fabric of Environmental Governance. Cambridge: Cambridge University Press.

Bodin, S.M.A., J. Baggio, M.L. Barnes, R. Berardo, G.S. Cumming, L.E. Dee et al. 2019. 'Improving Network Approaches to the Study of Complex Social-Ecological Interdependencies.' Nature Sustainability. doi:10.1038/s41893-019-0308-0.

Bohle, M., and R. Preiser. 2019. 'Exploring Societal Intersections of Geoethical Thinking.' In Exploring Geoethics, edited by M. Bohle, 71-136. New York: Springer. doi:10.1007/978-3-030-12010-8_3.

Cockburn, J., and G. Cundill. 2018. 'Ethics in Transdisciplinary Research: Reflections on the Implications of "Science with Society".' In The Palgrave Handbook of Ethics in Critical Research, edited by C.I. Macleod, J. Marx, P. Mnyaka, and G.J. Treharne, 81-97. New York: Springer. doi:10.1007/978-3-319-74721-7_6.

Colding, J., and S. Barthel. 2019. 'Exploring the Social-Ecological Systems Discourse 20 Years Later.' Ecology and Society 24(1): 2. doi:10.5751/ES-10598-240102.

Cox, M. 2015. 'A Basic Guide for Empirical Environmental Social Science.' Ecology and Society 20(1): 63. doi:10.5751/ES-07400-200163.

Creswell, J.W. 2014. A Concise Introduction to Mixed Methods Research. Thousand Oaks: Sage.

Cumming, G.S., and G.D. Peterson. 2017. 'Unifying Research on Social-Ecological Resilience and Collapse.' Trends in Ecology and Evolution. doi:10.1016/j.tree.2017.06.014.

Cvitanovic, C., M. Howden, R.M. Colvin, A. Norström, A.M. Meadow, and P.F.E. Addison. 2019. 'Maximising the Benefits of Participatory Climate Adaptation Research by Understanding and Managing the Associated Challenges and Risks.' Environmental Science and Policy. doi:10.1016/j. envsci.2018.12.028.

De Vos, A., R. Biggs, and R. Preiser. 2019. 'Methods for Understanding Social-Ecological Systems: A Review of Place-Based Studies.' Ecology and Society 24(4): 16. doi:10.5751/es-11236-240416.

Edmonds, B. 2017. 'Different Modelling Purposes.' In Simulating Social Complexity. Understanding Complex Systems, edited by B. Edmonds and R. Meyer, 39-58. New York: Springer. doi:10.1007/978-3-319-66948-9_4.

Fischer, J., T.A. Gardner, E.M. Bennett, P. Balvanera, R. Biggs, S. Carpenter, T. Daw et al. 2015. 'Advancing Sustainability through Mainstreaming a Social-Ecological Systems Perspective.' Current Opinion in Environmental Sustainability 14: 144-149. doi:10.1016/j.cosust.2015.06.002.

Haider, L.J., J. Hentati-Sundberg, M. Giusti, J. Goodness, M. Hamann, V.A. Masterson, M. Meacham et al. 2017. 'The Undisciplinary Journey: Early-Career Perspectives in Sustainability Science.' Sustainability Science (June): 1-14. doi:10.1007/s11625-017-0445-1.

Hazard, L., M. Cerf, C. Lamine, D. Le Magda, and P. Steyaert. 2019. 'A Tool for Reflecting on Research Stances to Support Sustainability Transitions.' Nature Sustainability (December). doi:10.1038/ s41893-019-0440-x.

Herrero-Jáuregui, C., C. Arnaiz-Schmitz, M. Reyes, M. Telesnicki, I. Agramonte, M. Easdale, M. Schmitz et al. 2018. 'What Do We Talk about When We Talk about Social-Ecological Systems? A Literature Review.' Sustainability 10(8). doi:10.3390/su10082950.

Jerneck, A., and L. Olsson. 2020. 'Theoretical and Methodological Pluralism in Sustainability Science.' In Framing in Sustainability Science: Theoretical and Practical Approaches, edited by T. Mino and S. Kudo. Singapore: Springer. doi:978-981-13-9061-6.

Kelly, R., M. Mackay, K.L. Nash, C. Cvitanovic, E.H. Allison, D. Armitage, A. Bonn et al. 2019. 'Ten Tips for Developing Interdisciplinary Socio-Ecological Researchers.' Socio-Ecological Practice Research 1(2): 149-161. doi:10.1007/s42532-019-00018-2.

Lang, D.J., A. Wiek, M. Bergmann, M. Stauffacher, P. Martens, P. Moll, M. Swilling, and C.J. Thomas. 2012. 'Transdisciplinary Research in Sustainability Science: Practice, Principles, and Challenges.' Sustainability Science 7(Supplement 1): 25-43. doi:10.1007/s11625-011-0149-x.

Leech, N.L., and A.J. Onwuegbuzie. 2009. 'A Typology of Mixed Methods Research Designs.' Quality and Quantity 43(2): 265-275. doi:10.1007/s11135-007-9105-3. 
Locke, T., N. Alcorn, and J. O’Neill. 2013. 'Ethical Issues in Collaborative Action Research.' Educational Action Research 21(1): 107-123. doi:10.1080/09650792.2013.763448.

McKim, C.A. 2017. 'The Value of Mixed Methods Research.' Journal of Mixed Methods Research 11(2): 202-222. doi:10.1177/1558689815607096.

Meijer, P.C., N. Verloop, and D. Beijaard. 2002. 'Multi-Method Triangulation in a Qualitative Study on Teachers' Practical Knowledge: An Attempt to Increase Internal Validity.' Quality \& Quantity 36.

Meyer, K., and R. Willis. 2019. 'Looking Back to Move Forward: The Value of Reflexive Journaling for Novice Researchers.' Journal of Gerontological Social Work. doi:10.1080/01634372.2018.1559906.

Meyfroidt, P. 2016. 'Approaches and Terminology for Causal Analysis in Land Systems Science.' Journal of Land Use Science. doi:10.1080/1747423X.2015.1117530.

Meyfroidt, P., R. Roy Chowdhury, A. de Bremond, E.C. Ellis, K.H. Erb, T. Filatova, R.D. Garrett et al. 2018. 'Middle-Range Theories of Land System Change.' Global Environmental Change 53: 52-67. doi:10.1016/j.gloenvcha.2018.08.006.

Minin, E.D., H. Tenkanen, and T. Toivonen. 2015. 'Prospects and Challenges for Social Media Data in Conservation Science.' Frontiers in Environmental Science 3(63). doi:10.3389/fenvs.2015.00063.

Mittelstadt, B.D., and L. Floridi. 2016. 'The Ethics of Big Data: Current and Foreseeable Issues in Biomedical Contexts.' Science and Engineering Ethics. doi:10.1007/s11948-015-9652-2.

Moore, C., J. Grewar, and G.S. Cumming. 2016. 'Quantifying Network Resilience: Comparison before and after a Major Perturbation Shows Strengths and Limitations of Network Metrics.' Journal of Applied Ecology 53(3): 636-645. doi:10.1111/1365-2664.12486.

Munafò, M.R., and G. Davey Smith. 2018. 'Repeating Experiments Is Not Enough.' Nature. doi:10.1038/d41586-018-01023-3.

Murray, G., L. D’Anna, and P. MacDonald. 2016. 'Measuring What We Value: The Utility of Mixed Methods Approaches for Incorporating Values into Marine Social-Ecological System Management.' Marine Policy 73: 61-68. doi:10.1016/J.MARPOL.2016.07.008.

Nash, K.L., C. Cvitanovic, E.A. Fulton, B.S. Halpern, E.J. Milner-Gulland, R.A. Watson, and J.L. Blanchard. 2017. 'Planetary Boundaries for a Blue Planet.' Nature Ecology and Evolution 1(11): 16251634. doi:10.1038/s41559-017-0319-z.

Norgaard, R.B. 1989. 'The Case for Methodological Pluralism.' Ecological Economics 1(1): 37-57. doi:10.1016/0921-8009(89)90023-2.

Norström, A.V., C. Cvitanovic, M.F. Löf, S. West, C. Wyborn, P. Balvanera, A.T. Bednarek et al. 2020. 'Principles for Knowledge Co-Production in Sustainability Research.' Nature Sustainability 3(3): 182-190. doi:10.1038/s41893-019-0448-2.

Österblom, H., B.I. Crona, C. Folke, M. Nyström, and M. Troell. 2017. 'Marine Ecosystem Science on an Intertwined Planet.' Ecosystems 20(1): 54-61. doi:10.1007/s10021-016-9998-6.

Pahl-Wostl, C., C. Giupponi, K. Richards, C. Binder, A. de Sherbinin, D. Sprinz, T. Toonen, and C. van Bers. 2013. 'Transition towards a New Global Change Science: Requirements for Methodologies, Methods, Data and Knowledge.' Environmental Science E Policy 28: 36-47. doi:10.1016/J. ENVSCI.2012.11.009.

Persson, J., A. Hornborg, L. Olsson, and H. Thorén. 2018. 'Toward an Alternative Dialogue between the Social and Natural Sciences.' Ecology and Society 23(4): 14. doi:10.5751/ES-10498-230414.

Popa, F., and M. Guillermin. 2017. 'Reflexive Methodological Pluralism.' Journal of Mixed Methods Research 11(1): 19-35. doi:10.1177/1558689815610250.

Poteete, A.R., M.A. Janssen, and E. Ostrom. 2010. Working Together: Collective Action, the Commons, and Multiple Methods. Princeton: Princeton University Press.

Preiser, R., R. Biggs, A. de Vos, and C. Folke. 2018. 'Social-Ecological Systems as Complex Adaptive Systems: Organizing Principles for Advancing Research Methods and Approaches.' Ecology and Society 23(4): 46.

Rambaldi, G., R. Chambers, M. McCall, and J. Fox. 2006. 'Practical Ethics for PGIS Practitioners, Facilitators, Technology Intermediaries and Researchers.' Participatory Learning and Action 54: 106113. https://pubs.iied.org/pdfs/G02957.pdf.

Rivera Lopez, F., F. Wickson, and V. Hausner. 2018. 'Finding CreativeVoice: Applying Arts-Based Research in the Context of Biodiversity Conservation.' Sustainability 10(6): 1778. doi:10.3390/su10061778.

Rossman, G.B., and S.F. Rallis. 2010. 'Everyday Ethics: Reflections on Practice.' International Journal of Qualitative Studies in Education 23(4): 379-391. doi:10.1080/09518398.2010.492813. 
Roux, D.J., J.L. Nel, G. Cundill, P.O’Farrell, and C. Fabricius. 2017. 'Transdisciplinary Research for Systemic Change: Who to Learn with, What to Learn about and How to Learn.' Sustainability Science 12(5): 711-726. doi:10.1007/s11625-017-0446-0.

Schlaepfer, M.A., M. Pascal, and M.A. Davis. 2011. 'How Might Science Misdirect Policy? Insights into the Threats and Consequences of Invasive Species.' Journal Fur Verbraucherschutz und Lebensmittelsicherheit 6(Supplement 1): 27-31. doi:10.1007/s00003-011-0690-7.

Schlüter, M., B. Müller, and K. Frank. 2019. 'The Potential of Models and Modeling for Social-Ecological Systems Research: The Reference Frame ModSES.' Ecology and Society 24(1): 31. doi:10.5751/ ES-10716-240131.

Schlüter, M., K. Orach, E. Lindkvist, R. Martin, N. Wijermans, Ö. Bodin, and W.J. Boonstra. 2019. 'Toward a Methodology for Explaining and Theorizing about Social-Ecological Phenomena.' Current Opinion in Environmental Sustainability. doi:10.1016/j.cosust.2019.06.011.

Shah, S.H., L. Rodina, J.M. Burt, E.J. Gregr, M. Chapman, S. Williams, N.J. Wilson, and G. McDowell. 2018. 'Unpacking Social-Ecological Transformations: Conceptual, Ethical and Methodological Insights.' The Anthropocene Review 5(3): 250-265. doi:10.1177/2053019618817928.

Skibins, J.C., J.C. Hallo, J.L. Sharp, and R.E. Manning. 2012. 'Quantifying the Role of Viewing the Denali "Big 5" in Visitor Satisfaction and Awareness: Conservation Implications for Flagship Recognition and Resource Management.' Human Dimensions of Wildlife 17: 112-128. doi:10.1080/ 10871209.2012.627531.

Stirling, A. 2015. 'Developing "Nexus Capabilities": Towards Transdisciplinary Methodologies.' doi:10.13140/RG.2.1.2834.9920.

Tashakkori, A., and C. Teddlie. 1998. Mixed Methodology: Combining Qualitative and Quantitative Approaches. Thousand Oaks: Sage.

Teddlie, C., and A. Tashakkori. 2011. 'Mixed Methods Research: Contemporary Issues in an Emerging Field.' In The SAGE Handbook of Qualitative Research, edited by N.K. Denzin and Y.S. Lincoln, 265-299. Thousand Oaks: Sage.

Tengö, M., E.S. Brondizio, T. Elmqvist, P. Malmer, and M. Spierenburg. 2014. 'Connecting Diverse Knowledge Systems for Enhanced Ecosystem Governance: The Multiple Evidence Base Approach.' Ambio 43(5): 579-591. doi:10.1007/s13280-014-0501-3.

Tengö, M., P. Malmer, P. Borraz, C. Cariño, J. Cariño, T. Gonzales, J. Ishizawa et al. 2012. 'Dialogue Workshop on Knowledge for the 21st Century: Indigenous Knowledge, Traditional Knowledge, Science and Connecting Diverse Knowledge Systems.' April. Usdub, Guna Yala, Panama.

Veldman, J.W., J.C. Aleman, S.T. Alvarado, T.M. Anderson, S. Archibald, W.J. Bond, T.W. Boutton, N. Buchmann, E. Buisson, J.G. Canadell, and De Sá Dechoum, M. 2019. 'Comment on "The Global Tree Restoration Potential”.' Science 366(6463). doi:10.1126/science.aay7976.

Weyer, B., J.C. Bezerra, and A. de Vos. 2019. 'Participatory Mapping in a Developing Country Context: Lessons from South Africa.' Land 8(9): 134. doi:10.3390/land8090134.

Wyborn, C., A. Datta, J. Montana, M. Ryan, P. Leith, B. Chaffin, C. Miller, and L. van Kerkhoff. 2019. 'Co-Producing Sustainability: Reordering the Governance of Science, Policy, and Practice.' Annual Review of Environment and Resources 44(1): 319-346. doi:10.1146/annurev-environ-101718-033103.

Young, O.R., F. Berkhout, G.C. Gallopin, M.A. Janssen, E. Ostrom, and S. van der Leeuw. 2006. 'The Globalization of Socio-Ecological Systems: An Agenda for Scientific Research.' Global Environmental Change 16(3): 304-316. doi:10.1016/j.gloenvcha.2006.03.004. 